\title{
Research on National Engineering Library Management Information System
}

\author{
Zhen Xu, and Yungao Wu, Wei Liu, Juanhua Zhai, Lei Zhang \\ Institute of Scientific \& Technical Information of China; Beijing 100038 \\ xuzhen, wuyungao, liuw, zhaijuanhua, zhanglei@istic.ac.cn
}

\begin{abstract}
Keywords: management information system, topology, function module, data flow
Abstract. This paper analyzes the business characteristics of the National Engineering Library and the problems on management information. Its work process is analyzed and optimized, and thus is put forward both the system's functional requirements and non-functional requirements. According to the demand analysis, the system architecture is built, and the functional structure, network topology, system security, data interface and a business module are designed. A new management information system is developed on the basis of optimization and reorganization of its business process. It mainly achieves the library daily purchasing, cataloging, circulation, collection, statistics and system management, and other functions. The system references to the mainstream of the current system design and trends of reference and starts from the actual business library. It is a set of economy applicable design with a complete independent intellectual property rights.
\end{abstract}

\section{Introduction}

Library management information system is the crucial tool to process mass information library staff. High level information management system can directly improve the institution of science and technology literature acquisition, cataloging, processing and service quality and efficiency. At present, the more well-known library management information system includes the management information system developed by OCLC company[1] and the Aleph500 system developed by Israeli company Ex Libris Ltd. have been widely applied in China[2], and the Systems are: the national digital Library engineering joint cataloging subsystem[3], China's higher education literature guarantee System (China Academic Library \& Information System, CALIS) [4], under the leadership of Ministry of Culture of Library Automation Integrated System (ILAS) [5], Jiangsu Analyses System[6] and Bei You System etc. [7]These management information systems are playing an important role in a range of scenarios. However, they also suffer from lots of shortcomings, such as high cost, technical barriers, poor stability.

Since its establishment, National Engineering Library is based on the principle of independently controlled, economy applicable and have conducted the development of management information system which has experienced the first phase of system construction and the second phase of system transformation. A network has been basically built which can provide stable services. The current mainstream of information technology, internal standard networking and information sharing can satisfy the actual business development needs of multi-function management information system. National Engineering and Technology Digital Library website is shown in Figure 1. 


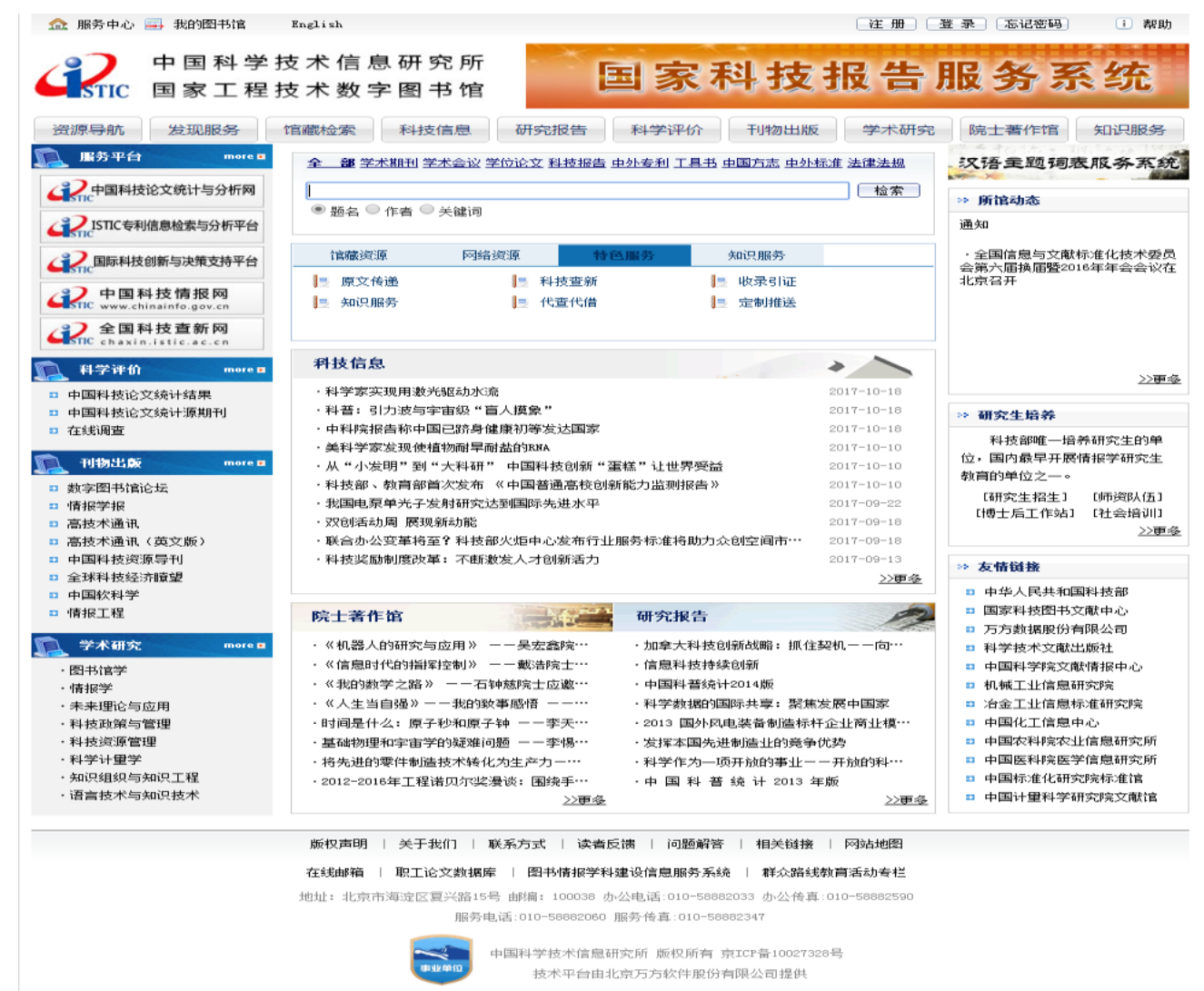

Figure 1. The Official Website of National Engineering and Technology Digital Library

\section{Main Business Flow Construction}

The National Engineering Library management information system must conform to the actual business work requirements of the library. The core business of the National Engineering Library includes: placing orders, bidding and purchasing literatures, book acceptance, classification, cataloguing, data processing, information release, the management and service of the readers, and the statistics analysis of the related work. Library work respectively by publishers, different departments of the library, readers and circulation service and who closely cooperate to do together, there is a close business ties between them. The main business process is shown in Figure 2. 


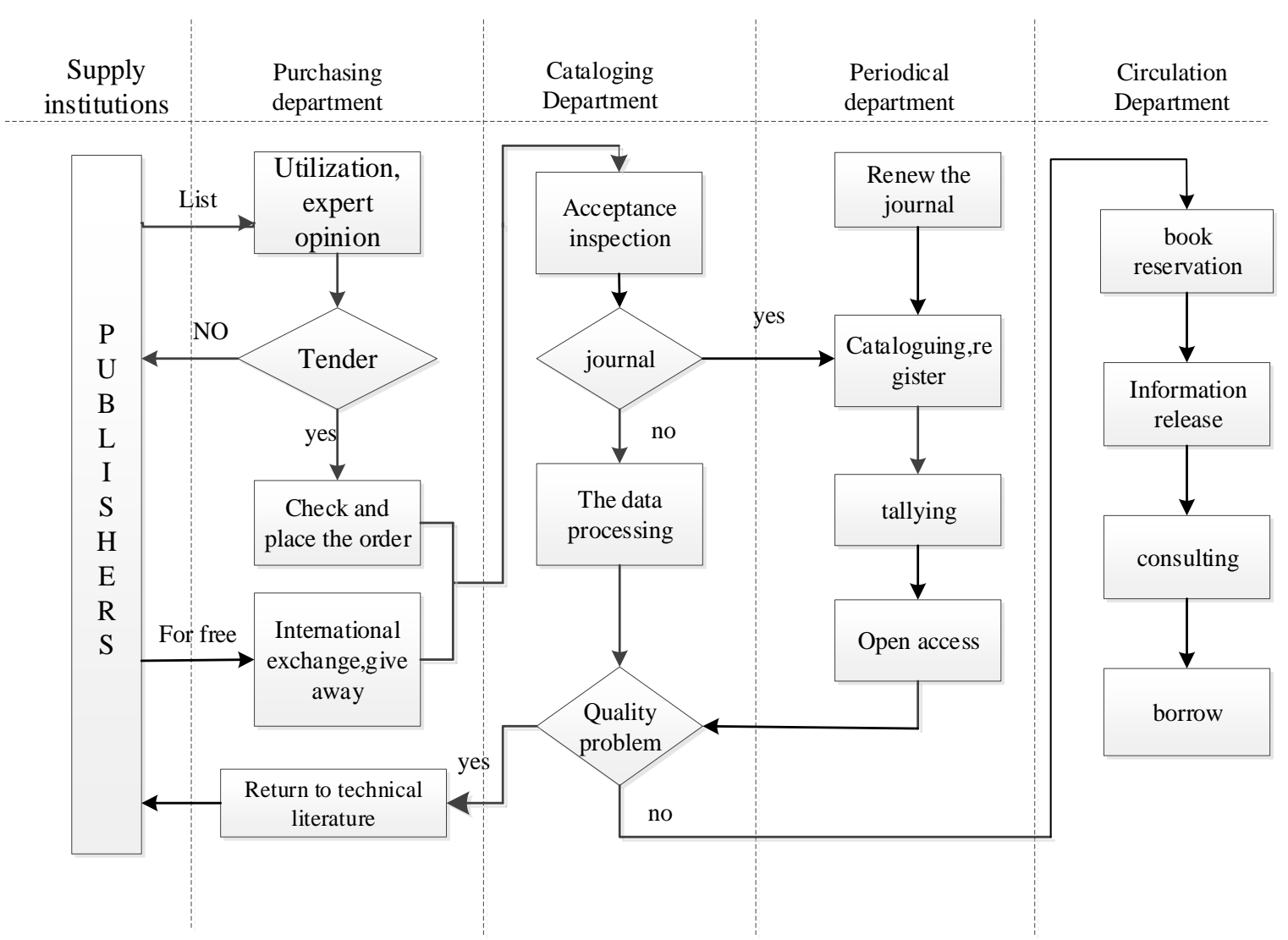

Figure 2. Main business flow chart of The National Engineering Library

Purchasing department is responsible for the purchasing and collection of science and technology literatures, the staffs of the purchasing department are divided into the staffs of collecting western literatures, the staffs of the collecting periodical and the staffs of collecting databases. The purchasing continuity publications of the famous dealers is main way of collecting by centralized bidding procurement. Meet the library collection needs and reasonable price is necessary, and then check repetition and place orders, post code mark and record invoice number after repentance as a description of the registration of state-owned assets. The literatures are sent to the cataloguing department after the literature classification, and periodical literatures as an independent resource is directly sent to the periodicals department and will be left the basic information of the books for relevant information in search system of the database and to facilitate the reader's borrowing and obtaining.

After the completion of inspection quality, book data is delivered to literature circulation consulting for collection and service. The entire literature data is released, and readers can search it via online National Engineering Library.

\section{System Architecture}

According to the main business processes of the library, our national engineering library management information system architecture is composed of the data layer, the business logic layer and the showing layer. Among them, the data layer is the data and related applications that are responsible for storing the various business processes of the design. The business logic layer is the library and background data processing and business management platform, can be divided into literature journal purchasing and cataloguing, literature collection, management, distribution management, release management, statistics management and system management of eight modules. The system showing layer is the platform for the information disclosure of library business activities and the communication with readers. The system architecture is shown in Figure 3. 


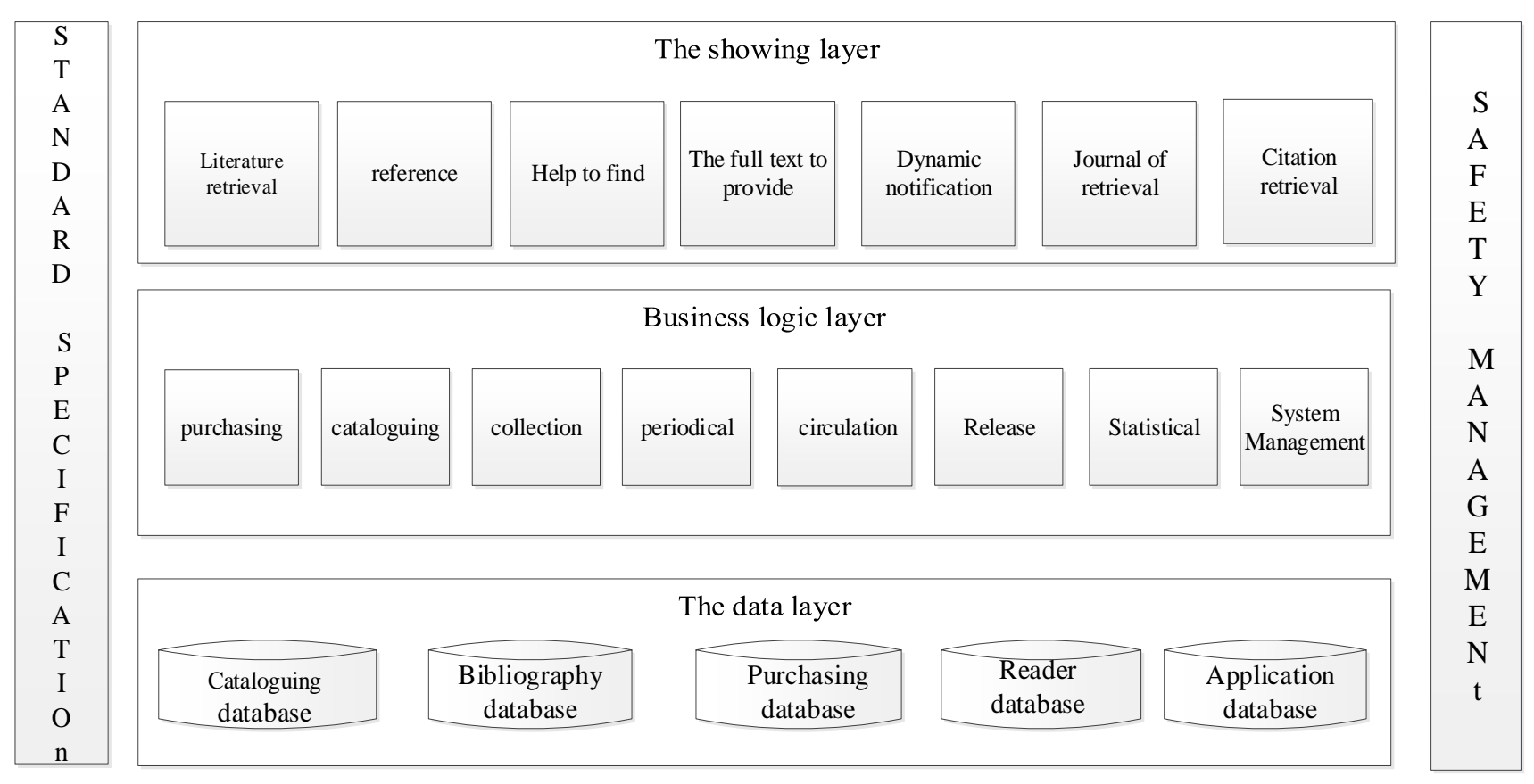

Figure 3. System architecture diagram

\section{System Function Modules}

This system consists of eight functional modules which are purchasing module, cataloguing module, literature collection module, circulation management module, periodical management module, release management module, statistics management module, system management module. The overall system function is shown in Figure 4.

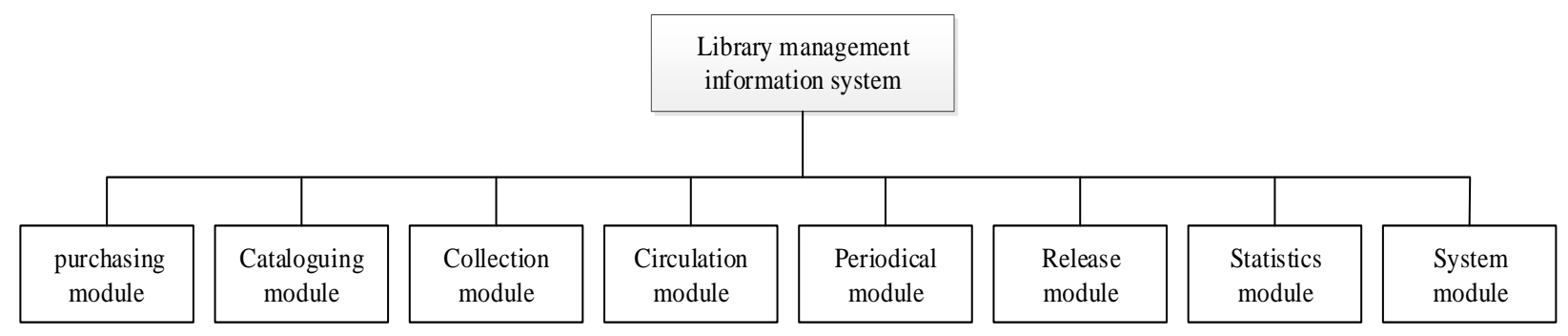

Figure 4. Functions of library system

The purchasing module shall conduct bidding procurement according to the research needs of national science and technology strategy and expert guidance. The cataloging module is used to carry out artificial data identification, recording and extraction of descriptive information for the purpose of retrieval, statistics and services of the literature. The main task of the collection module is to be responsible for the collection, distribution and scanning of the library. The circulation module receives and accepts the collection of scientific and technical documents. The periodical module collects the periodical of each source way from nationwide periodical publisher for free. The function of information release module includes five modules: information release, information audit, information deletion, information storage and evaluation management. The statistical module is to make statistics on its own work situation and various business. The system module is responsible for the operation and control of related system processes. 


\section{System Network Topology Diagram}

In the construction of the library management system network topology structure, the main consideration of the factors is: the response speed of the network system, the ability of processing data (the data flow, data throughput, the network client visits), the convenience degree of each department, labor cooperation, safety, stability and scalability of the network, etc. The topology of network system is shown in Figure 5.

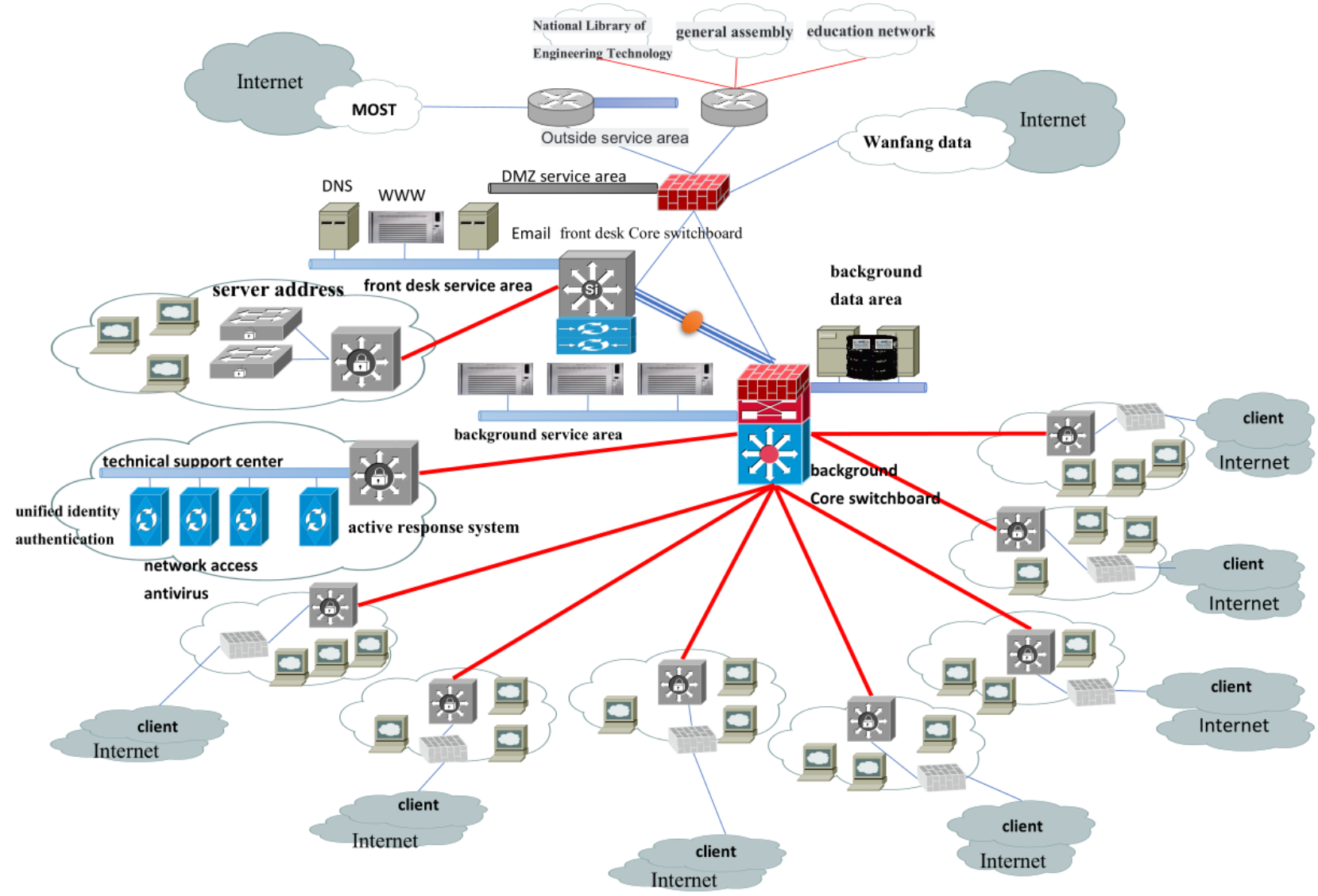

Figure 5. Topology diagram of network system

For the flow consideration, the internet access adopts 1000M fiber, and the center switch and all the main switch adopt optical cable.10-100M cables are used to get to each switch, and the network adaptor uses gigabit adaptive network card and a 100mb speed CISCO6509 wireless routing equipment. For the security consideration, the structure design of the internal network is separated from the external network, and the office of the professional or high-level staff is separated from that of the general staff. To ensure safety, the corresponding security center and network management center are built, including hardware firewall and software firewall. In view of the wireless local area network (LAN), corresponding encryption measures are used, to ensure the security of the information. For the extensibility consideration, the main body adopts the star network topology structure, which provides good expansibility for the later IT equipment.

\section{Interface Design}

\section{System Interface Design}

The library establishes a shared resource platform through the management information system. System integration should be from the viewpoint of the integrity, comprehending and coordinating various parts, making them together to achieve the overall optimal. The relationship diagram of library system collection module and the other modules is shown in Figure 6. 


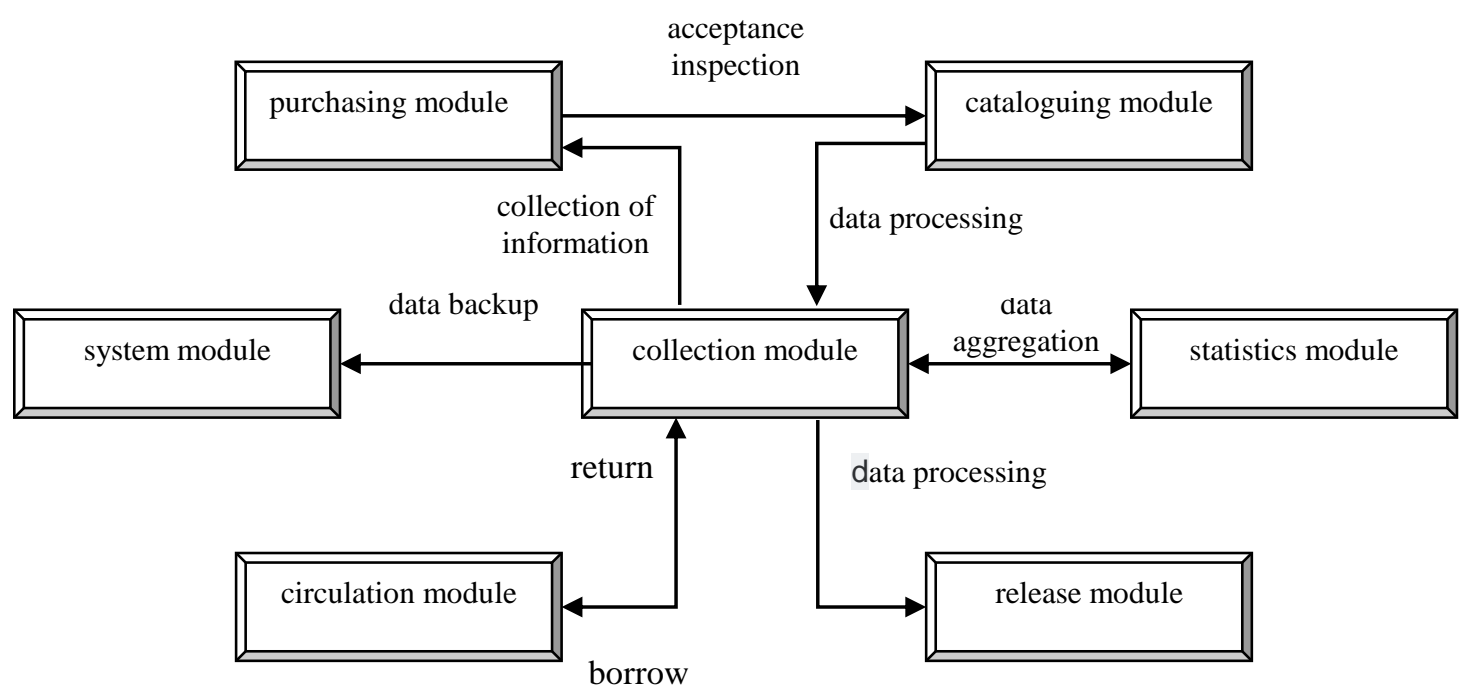

Figure 6. relationship diagram of library system

Library management information system uses JMS message technology implementation for asynchronous, non-real-time, small amount of data interface, and uses Web Service technology for synchronization, real-time, and small amount of data interface. Batch data interface is really based on a file or shared data table mechanism.

\section{External Interface Design}

The purpose of library to provide technical support and services for outside readers is mainly for relevance ranking, download flow filtering, user self-tagging and the realizing of the function such as navigation. This system adopts the ProQuest, Serials Solutions, Summon 2.0 interface technology. It can make the junior and senior researchers rapidly gaining valuable scientific research information. Although the users cannot grasp and control all of its precise semantic vocabularies and its automatically extended query function, they can ensure that they do not leave out any related content. The main representative library system interface is shown in Table 1.

Table 1 main representative library system interface comparison table

\begin{tabular}{|c|c|c|}
\hline $\begin{array}{l}\text { Development } \\
\text { company }\end{array}$ & $\begin{array}{l}\text { Library } \\
\text { interface }\end{array}$ & The main features \\
\hline $\begin{array}{l}\text { Inovative } \\
\text { Interfaces }\end{array}$ & Encore & $\begin{array}{l}\text { Based on the theme title, the interface tag cloud and surface navigation } \\
\text { function, provides dynamic generation of popular options. }\end{array}$ \\
\hline Ex Libris & Primo & $\begin{array}{l}\text { Designed for large academic libraries, the system architecture } \\
\text { includes integrated link parsers, federated retrieval and electronic } \\
\text { resource transfer features. Provides page navigation and relevancy } \\
\text { sorting results. }\end{array}$ \\
\hline VTLS & Visualizer & $\begin{array}{l}\text { "Fully exposed" access resources, including collection catalogs, } \\
\text { institutional repositories, local digital resources, etc. }\end{array}$ \\
\hline Auto-Graphics & $\begin{array}{l}\text { Agent } \\
\text { Illuminar }\end{array}$ & $\begin{array}{l}\text { The first graphical desktop environment based on the Adobe Flex } \\
\text { framework. }\end{array}$ \\
\hline $\begin{array}{l}\text { The Library } \\
\text { Corporation }\end{array}$ & LS2 PAC & $\begin{array}{l}\text { The first available ILS product for TLC. The visual front-end } \\
\text { interface realizes user tagging, relevant sorting and tagging, } \\
\text { commenting, narrowing results, and location map displaying. }\end{array}$ \\
\hline $\begin{array}{l}\text { Serials } \\
\text { Solutions }\end{array}$ & Summon & $\begin{array}{l}\text { Access to the library all resources, including books, literature level } \\
\text { of electronic publications, any local management of storage or } \\
\text { digital resources, electronic content and journal full text search. }\end{array}$ \\
\hline SirsiDynix & Enterprise & $\begin{array}{l}\text { be able to perform fuzzy matching searching, correlation result } \\
\text { sorting. }\end{array}$ \\
\hline
\end{tabular}




\section{Conclusions}

This paper introduces the business characteristics of the National Engineering Library and discusses the related issues. The work flow of the management information is analyzed and optimized, the functional and non-functional requirements of the system are proposed. The system architecture is built according to the demand, and the functional structure, network topology, system security, data interface and a business module are designed. A set of practical management information system based on optimization and reorganization of its business processes established which mainly realizes the library's purchasing, cataloging, circulation, collection, statistics and system management, and other functions. The system which refers to the mainstream trend of the current system design and and stems from the actual businesses of the National Engineering Library is a set of economy applicable design plan possessing completely independent intellectual property rights.

\section{Acknowledgements}

This work was partially supported by National construction project of China engineering science and technology knowledge center - knowledge organization system construction(CKCEST-2017-1-12).

\section{References}

[1] Niu Aiju, Yang Xueping, Qingwei et al. Comparative study on the management and service function of interlibrary mutual loan system, taking OCLC and CASHL as an example [J]. Journal of University Library, 2014, 34(4):63-68,12.

[2] liu sha. The analysis of the problem of the system ordering of the Hong Kong books in the system of the interview with ALEPH500 [J]. University Library, 2015, (5):40-44.

[3] Shen Xiaojuan, Qi Xin. An overview of national digital library engineering [J]. National Library Journal, 2008,17(3):7-11.

[4] Xiao Long, Chen Ling. CALIS and the development of digital library in Chinese universities [J]. Book Intelligence, 2005,49(11):9-14.

[5] Chen Dingquan. ILAS thirty years (1985-2015): development history and future direction [J]. Library BBS, 2016, (6):34-42,26.

[6] Ma Hongwei. The trend of library automation management from huiwen system [J]. Library Theory and Practice, 2006, (6):27-28.

[7] Wu Jiangli. Chen haiyan, lu cailing et al. Comparative study on the subsystem function of the north mail system [J]. Modern Intelligence, 2007,27(3):161-163. 